\title{
General Randić, Sum-Connectivity, Hyper-Zagreb and Harmonic Indices, and Harmonic Polynomial of Molecular Graphs
}

\author{
Mohammad Reza Farahani, ${ }^{1}$ Wei Gao, ${ }^{2}$ M. R. Rajesh Kanna, \\ R. Pradeep Kumar, ${ }^{4}$ and Jia-Bao Liu ${ }^{5}$ \\ ${ }^{1}$ Department of Applied Mathematics, Iran University of Science and Technology (IUST) Narmak, \\ Tehran 16844, Iran \\ ${ }^{2}$ School of Information Science and Technology, Yunnan Normal University, Kunming 650500, China \\ ${ }^{3}$ Department of Mathematics, Maharani's Science College for Women, Mysore 570005, India \\ ${ }^{4}$ Department of Mathematics, The National Institute of Engineering, Mysuru 570008, India \\ ${ }^{5}$ School of Mathematics and Physics, Anhui Jianzhu University, Hefei 230601, China
}

Correspondence should be addressed to Mohammad Reza Farahani; mrfarahani88@gmail.com

Received 7 July 2016; Accepted 30 August 2016

Academic Editor: Dennis Salahub

Copyright (C) 2016 Mohammad Reza Farahani et al. This is an open access article distributed under the Creative Commons Attribution License, which permits unrestricted use, distribution, and reproduction in any medium, provided the original work is properly cited.

We present explicit formula for the general Randić connectivity, general sum-connectivity, Hyper-Zagreb and Harmonic Indices, and Harmonic polynomial of some simple connected molecular graphs.

\section{Introduction}

In this paper, we consider only simple connected graphs without loops and multiple edges. A connected graph is a graph such that there is a path between all pairs of vertices. Let $G=(V, E)$ be an arbitrary simple connected graph; we denote the vertex set and the edge set of $G$ by $V(G)$ and $E(G)$, respectively. For two vertices $u$ and $v$ of $V(G)$, the distance between $u$ and $v$ is denoted by $d(u, v)$ and defined as the length of any shortest path connecting $u$ and $v$ in $G$. For a vertex $v$ of $V(G)$, the degree of $v$ is denoted by $d_{v}$ and is the number of vertices of $G$ adjacent to $v$.

In chemical graph theory, we have many invariant polynomials and topological indices for a molecular graph. A topological index is a numerical value for correlation of chemical structure with various physical properties, chemical reactivity, or biological activity [1-3].

One of the oldest topological indices or molecular descriptors is the Zagreb index that has been introduced more than forty years ago by Gutman and Trinajstić in 1972 [4].
Now, we know that, for a molecular graph $G=(V, E)$, the first Zagreb index $M_{1}(G)$ and the second Zagreb index $M_{2}(G)$ are defined as

$$
\begin{aligned}
M_{1}(G) & =\sum_{v \in V(G)}\left(d_{v}\right)^{2}, \\
\text { or } M_{1}(G) & =\sum_{e=u v \in E(G)}\left(d_{u}+d_{v}\right), \\
M_{2}(G) & =\sum_{e=u v \in E(G)}\left(d_{u} \times d_{v}\right) .
\end{aligned}
$$

Recently, a new version of Zagreb indices named HyperZagreb index was introduced by Shirdel et al. in 2013 [5] and it is defined as

$$
H M(G)=\sum_{e=u v \in E(G)}\left(d_{u}+d_{v}\right)^{2} .
$$

We encourage the reader to consult [6-30] for historical background and mathematical properties of the Zagreb indices. 
In 1975, Randić proposed a structural descriptor called the branching index [31] that later became the well-known Randić molecular connectivity index. Motivated by the definition of Randić connectivity index based on the end-vertex degrees of edges in a graph defined as the sum of the weights $\left(d_{u} d_{v}\right)^{-1 / 2}$ of all edges $u v$ of $G$

$$
R(G)=\sum_{e=u v \in E(G)} \frac{1}{\sqrt{d_{u} d_{v}}} .
$$

Later, the Randić connectivity index had been extended as the general Randić connectivity index, which is defined as the sum of the weights $\left(d_{u} d_{v}\right)^{\alpha}(\forall \alpha \in \mathbb{Q})$ and is equal to

$$
R^{\alpha}(G)=\sum_{e=u v \in E(G)}\left(d_{u} d_{v}\right)^{\alpha} .
$$

Also, a closely related variant of Randić connectivity index called the sum-connectivity index was introduced by Zhou and Trinajstić in 2008 [32, 33]. The sum-connectivity index $X(G)$ is defined as

$$
X(G)=\sum_{u v \in E(G)} \frac{1}{\sqrt{d_{u}+d_{v}}} .
$$

The general sum-connectivity index of a graph $G$ is equal to $(\forall \alpha \in \mathbb{Q})$

$$
X^{\alpha}(G)=\sum_{e=u v \in E(G)}\left(d_{u}+d_{v}\right)^{\alpha}
$$

In 1987 [34], Fajtlowicz introduced the Harmonic index $H(G)$ of a graph $G$ which is defined as the sum of the weights $2\left(d_{u} d_{v}\right)^{-1}$ of $\forall u v \in G$ and is equal to

$$
H(G)=\sum_{e=u v \in E(G)} \frac{2}{d_{u}+d_{v}} .
$$

The Harmonic index is one of the most important indices in chemical and mathematical fields. It is a variant of the Randić index which is the most successful molecular descriptor in structure-property and structure activity relationships studies. The Harmonic index gives somewhat better correlations with physical and chemical properties compared with the well-known Randić index. Estimating bounds for $H(G)$ is of great interest, and many results have been obtained. For example, Favaron et al. [35] considered the relationship between the Harmonic index and the eigenvalues of graphs, and Zhong [36-38] determined the minimum and maximum values of the Harmonic index for simple connected graphs, trees, unicyclic graphs, and bicyclic graphs and characterized the corresponding extremal graphs, respectively. It turns out that trees with maximum and minimum Harmonic index are the path $P_{n}$ and the star $S_{n}$, respectively.
Recently, Iranmanesh and Salehi [39] introduced the Harmonic polynomial $H(G, x)$ of a graph $G$ which is equal to

$$
H(G, x)=\sum_{e=u v \in E(G)} 2 x^{\left(d_{v}+d_{v}-1\right)}
$$

where $H(G)=\int_{0}^{1} H(G, x) d x$.

We encourage the reader to consult [40-43] for more history and mathematical properties of the Randić index and the Harmonic index.

In this paper, we present explicit formula for the general Randić connectivity, general sum-connectivity, HyperZagreb and Harmonic Indices, and Harmonic polynomial of some hydrocarbon molecular graphs.

\section{Results and Discussion}

In this section, we compute the general Randić connectivity, general sum-connectivity indices, the Hyper-Zagreb and Harmonic Indices, and Harmonic polynomial of a family of hydrocarbon molecules, which are called Polycyclic Aromatic Hydrocarbons $\mathrm{PAH}_{k}(\forall k \in \mathbb{N})$.

The Polycyclic Aromatic Hydrocarbons $\mathrm{PAH}_{k}$ is a family of hydrocarbon molecules, such that its structure is consisting of cycles with length six (benzene). The Polycyclic Aromatic Hydrocarbons can be thought of as small pieces of graphene sheets with the free valences of the dangling bonds saturated by $H$. Vice versa, a graphene sheet can be interpreted as an infinite PAH molecule. Successful utilization of PAH molecules in modeling graphite surfaces has been reported earlier [44-52] and references therein. Some first members and a general representation of this hydrocarbon molecular family are shown in Figures 1 and 2.

Theorem 1 (see [45]). Consider the Polycyclic Aromatic Hydrocarbons $\mathrm{PAH}_{k}(\forall k \in \mathbb{N})$. Then, the first and second Zagreb indices of $\mathrm{PAH}_{k}$ are equal to

$$
\begin{aligned}
& M_{1}\left(P A H_{k}\right)=54 k^{2}+6 k \\
& M_{1}\left(P A H_{k}\right)=81 k^{2}-3 k
\end{aligned}
$$

Theorem 2. The Hyper-Zagreb index of Polycyclic Aromatic Hydrocarbons $\mathrm{PAH}_{k}(\forall k \in \mathbb{N})$ is equal to

$$
H M\left(\mathrm{PAH}_{k}\right)=12 k(27 k-1) \text {. }
$$

Theorem 3 (see [46]). The Randić connectivity and sumconnectivity indices of the Polycyclic Aromatic Hydrocarbons $\mathrm{PAH}_{k}(\forall k \in \mathbb{N})$ are equal to

$$
\begin{aligned}
& R\left(P A H_{k}\right)=3 k 2+(2 \sqrt{3}-1) k, \\
& X\left(P A H_{k}\right)=\frac{n}{2}(3 \sqrt{6} n+6-\sqrt{6}) .
\end{aligned}
$$



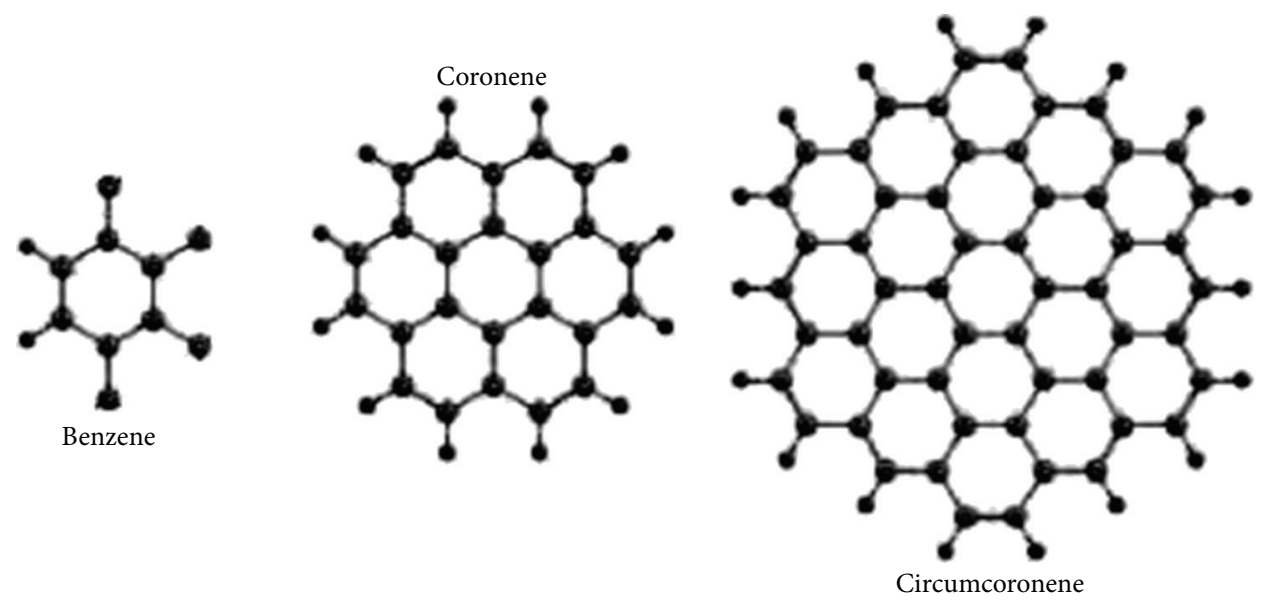

Figure 1: Some first members of the Polycyclic Aromatic Hydrocarbons $\left(\mathrm{PAH}_{k}\right)$.

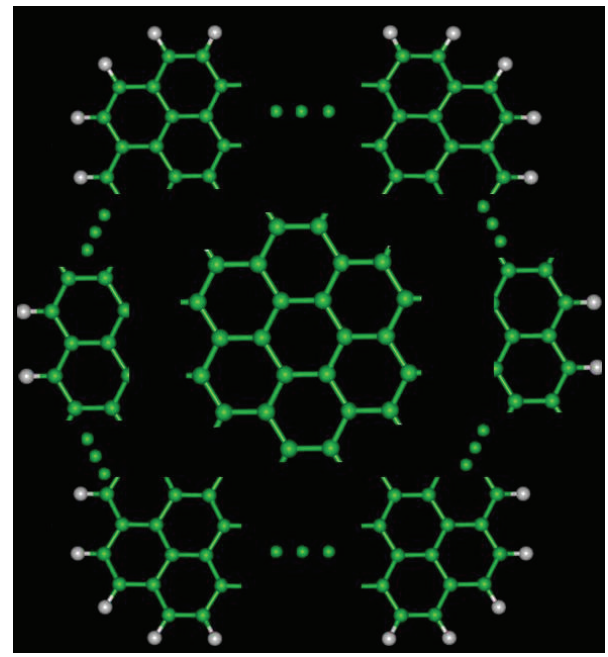

FIGURE 2: A general representation of the hydrocarbon molecular family "Polycyclic Aromatic Hydrocarbons, $\mathrm{PAH}_{k}$ ".

Theorem 4. Let $\mathrm{PAH}_{k}$ be the Polycyclic Aromatic Hydrocarbons. Then,

(i) the general Randic connectivity index of $\mathrm{PAH}_{k}$ is equal to

$$
R^{\alpha}\left(P A H_{k}\right)=3 k\left(3^{2 \alpha+1} k+3^{\alpha}\left(2-3^{\alpha}\right)\right),
$$

(ii) the general sum-connectivity index of $\mathrm{PAH}_{k}$ is equal to

$$
X^{\alpha}\left(P A H_{k}\right)=2^{\alpha} 3 k\left(3^{\alpha+1} k-3^{\alpha}+2^{\alpha+1}\right) \text {. }
$$

Theorem 5. Consider the Polycyclic Aromatic Hydrocarbons $\mathrm{PAH}_{k}$. Then,

(i) the Harmonic index of $\mathrm{PAH}_{k}$ is equal to $\forall k \in \mathbb{N}$ :

$$
H\left(P A H_{k}\right)=3 k^{2}+2 k
$$

(ii) the Harmonic polynomial of $\mathrm{PAH}_{k}$ is equal to $\forall k \in \mathbb{N}$ :

$$
H\left(P A H_{k}, x\right)=12 k x^{3}+6 k(3 k-1) x^{5} .
$$

Before presenting the main results, consider the following definition.

Definition 6 (see [10]). Let $G$ be a simple connected molecular graph. We divide the vertex set $V(G)$ and edge set $E(G)$ of $G$ based on the degrees $d_{v}$ of a vertex/atom $v$ in $G$. Obviously, $1 \leq d_{v} \leq n-1$ and we denote the minimum and maximum of the $d_{v}$ by $\delta$ and $\Delta$, respectively:

$$
\begin{aligned}
& V_{k}=\left\{v \in V(G) \mid d_{v}=k\right\} \quad \forall k: \delta \leq k \leq \Delta, \\
& E_{i}=\left\{e=u v \in E(G) \mid d_{u}+d_{v}=i\right\}
\end{aligned}
$$$$
\forall i: 2 \delta \leq i \leq 2 \Delta
$$

$$
E_{j}^{*}=\left\{u v \in E(G) \mid d_{u} \times d_{v}=j\right\} \quad \forall j: \delta^{2} \leq j \leq \Delta^{2} .
$$

Proof of Theorem 2. Let $\mathrm{PAH}_{k}$ be the Polycyclic Aromatic Hydrocarbon for all integer numbers $k$. From the general representation of $\mathrm{PAH}_{k}$ in Figure 2, one can see that in this hydrocarbon molecular family there are $6 k^{2}+6 k$ vertices/atoms $\left(=\left|V\left(\mathrm{PAH}_{k}\right)\right|\right)$ such that $6 k^{2}$ of them are carbon atoms and also $6 k$ of them are hydrogen atoms. In other words,

$$
\begin{aligned}
& V_{3}=V_{C}=\left\{v \in V\left(\mathrm{PAH}_{k}\right) \mid d_{v}=3\right\}, \\
& V_{1}=V_{H}=\left\{v \in V\left(\mathrm{PAH}_{k}\right) \mid d_{v}=1\right\} .
\end{aligned}
$$

Thus, there are $\left(3 \times 6 k^{2}+1 \times 6 k\right) / 2=9 k^{2}+3 k$ edges/chemical bonds $\left(=\left|E\left(\mathrm{PAH}_{n}\right)\right|\right)$ in $\mathrm{PAH}_{k}$.

Now, by using Definition 6 and according to Figure 2, one can see that in hydrocarbon molecules $\mathrm{PAH}_{k}$ all hydrogen atoms have one connection and the degree of them is $d_{\text {Hydrogen }}=1$ and there are 3 edges/chemical bonds for all carbon atoms; thus, $d_{\text {Carbon }}=3$.

Therefore, we have two partitions of the vertex set $V\left(\mathrm{PAH}_{n}\right)$ of Polycyclic Aromatic. 
Hydrocarbons $\mathrm{PAH}_{k}$ are as follows:

$$
\begin{aligned}
E_{4} & =E_{3}^{*} \\
& =\left\{e=u v=H C \in E\left(\mathrm{PAH}_{n}\right) \mid d_{H}=1, d_{C}=3\right\}, \\
E_{6} & =E_{9}^{*} \\
& =\left\{e=u v=C C \in E\left(\mathrm{PAH}_{n}\right) \mid d_{C}=d_{C}=3\right\} .
\end{aligned}
$$

On the other hand, from Figure 2 and $[45,46]$, we can see that $\left|E_{4}\right|=\left|E_{3}^{*}\right|=6 k$ and $\left|E_{6}\right|=\left|E_{9}^{*}\right|=9 k^{2}-3 k$.

Here, we have the following computations for the HyperZagreb index of the Polycyclic Aromatic Hydrocarbons $\mathrm{PAH}_{k}(\forall k \in \mathbb{N})$ as follows:

$$
\begin{aligned}
H M\left(\mathrm{PAH}_{k}\right)= & \sum_{e=u v \in E\left(\mathrm{PAH}_{k}\right)}\left(d_{u}+d_{v}\right)^{2} \\
= & \sum_{u v \in E_{4} \subseteq E\left(\mathrm{PAH}_{k}\right)}\left(d_{u}+d_{v}\right)^{2} \\
& +\sum_{u v \in E_{6} \subseteq E\left(\mathrm{PAH}_{k}\right)}\left(d_{u}+d_{v}\right)^{2} \\
= & \sum_{u v \in E_{4} \subseteq E\left(\mathrm{PAH}_{k}\right)}\left(d_{C}+d_{H}\right)^{2} \\
& +\sum_{u v \in E_{6} \subseteq E\left(\mathrm{PAH}_{k}\right)}\left(d_{C}+d_{C}\right)^{2} \\
= & 16 \times\left|E_{4}\right|+36 \times\left|E_{6}\right| \\
= & 16 \times(6 k)+36 \times\left(9 k^{2}-3 k\right) \\
= & 12 k(27 k-1) .
\end{aligned}
$$

Here, we complete the proof of Theorem 2.

Proof of Theorem 4. Consider the Polycyclic Aromatic Hydrocarbons $\mathrm{PAH}_{k}$ with $6 k^{2}+6 k$ vertices/atoms and $9 k^{2}+3 k$ edges. Then, by using the results from the above proof, we have the following computations for the general Randić and sum-connectivity indices of $\mathrm{PAH}_{k}(\forall k \in \mathbb{N}, \forall \alpha \in \mathbb{Q})$ :

$$
\begin{aligned}
R^{\alpha}\left(\mathrm{PAH}_{k}\right) & =\sum_{e=u v \in E\left(\mathrm{PAH}_{k}\right)}\left(d_{u} d_{v}\right)^{\alpha} \\
& =\sum_{H C \in E_{3}^{*}}\left(d_{H} d_{C}\right)^{\alpha}+\sum_{C C \in E_{9}^{*}}\left(d_{C} d_{C}\right)^{\alpha} \\
& =\left|E_{3}^{*}\right| \times(3)^{\alpha}+\left|E_{9}^{*}\right| \times(9)^{\alpha} \\
& =3^{\alpha}(6 k)+3^{2 \alpha}\left(9 k^{2}-3 k\right) \\
& =3 k\left(3^{2 \alpha+1} k+3^{\alpha}\left(2-3^{\alpha}\right)\right) \\
X^{\alpha}\left(\mathrm{PAH}_{k}\right) & =\sum_{e=u v \in E\left(\mathrm{PAH}_{k}\right)}\left(d_{u}+d_{v}\right)^{\alpha} \\
& =\sum_{H C \in E_{4}}\left(d_{H}+d_{C}\right)^{\alpha}+\sum_{C C \in E_{6}}\left(d_{C}+d_{C}\right)^{\alpha}
\end{aligned}
$$

$$
\begin{aligned}
& =\left|E_{4}\right| \times(4)^{\alpha}+\left|E_{6}\right| \times(6)^{\alpha} \\
& =2^{2 \alpha}(6 k)+6^{\alpha}\left(9 k^{2}-3 k\right) \\
& =2^{\alpha} 3 k\left(3^{\alpha+1} k-3^{\alpha}+2^{\alpha+1}\right) .
\end{aligned}
$$

Proof of Theorem 5. Let $\mathrm{PAH}_{k}$ be the Polycyclic Aromatic Hydrocarbon for all integer numbers $k$. By results from proof of Theorem 2, we see that the Harmonic index and Harmonic polynomial of $\mathrm{PAH}_{k}(\forall k \in \mathbb{N})$ are equal to

$$
\begin{aligned}
& H\left(\mathrm{PAH}_{k}\right)=\sum_{u v \in E\left(\mathrm{PAH}_{k}\right)} \frac{2}{d_{u}+d_{v}} \\
& =\sum_{u v \in E\left(\mathrm{PAH}_{k}\right)} \frac{2}{d_{u}+d_{v}} \\
& +\sum_{u v \in E\left(\mathrm{PAH}_{k}\right)} \frac{2}{d_{u}+d_{v}} \\
& =\sum_{u v \in E_{4}} \frac{2}{d_{H}+d_{C}}+\sum_{u v \in E_{6}} \frac{2}{d_{C}+d_{C}} \\
& =\frac{2}{4}\left|E_{4}\right|+\frac{2}{6}\left|E_{6}\right| \\
& =\frac{2}{4}(6 k)+\frac{2}{6}\left(9 k^{2}-3 k\right) \\
& =3 k+\left(3 k^{2}-k\right)=3 k^{2}+2 k, \\
& H\left(\mathrm{PAH}_{k}, x\right)=\sum_{u v \in E\left(\mathrm{PAH}_{k}\right)} 2 x^{\left(d_{v}+d_{v}-1\right)} \\
& =\sum_{H C \in E_{4}} 2 x^{\left(d_{H}+d_{C}-1\right)} \\
& +\sum_{C C \in E_{6}} 2 x^{\left(d_{C}+d_{C}-1\right)} \\
& =2\left|E_{4}\right| x^{3}+2\left|E_{6}\right| x^{5} \\
& =12 k x^{3}+6 k(3 k-1) x^{5} \text {. }
\end{aligned}
$$

Here, the proof of Theorem 5 was completed.

\section{Competing Interests}

The authors declare that there is no conflict of interests regarding the publication of this paper.

\section{Acknowledgments}

The authors are thankful to Professor Mircea V. Diudea, Faculty of Chemistry and Chemical Engineering, BabesBolyai University, for his precious support and suggestions. 


\section{References}

[1] H. Wiener, "Structural determination of paraffin boiling points," Journal of the American Chemical Society, vol. 69, no. 1, pp. 1720, 1947.

[2] D. B. West, Introduction to Graph Theory, Prentice Hall, 1996.

[3] R. Todeschini and V. Consonni, Handbook of Molecular Descriptors, John Wiley \& Sons, Weinheim, Germany, 2000.

[4] N. Trinajstić, Chemical Graph Theory, Mathematical Chemistry Series, CRC Press, Boca Raton, Fla, USA, 2nd edition, 1992.

[5] I. Gutman and N. Trinajstić, "Graph theory and molecular orbitals. Total $\varphi$-electron energy of alternant hydrocarbons," Chemical Physics Letters, vol. 17, no. 4, pp. 535-538, 1972.

[6] G. H. Shirdel, H. RezaPour, and A. M. Sayadi, "The hyperzagreb index of graph operations," Iranian Journal of Mathematical Chemistry, vol. 4, no. 2, pp. 213-220, 2013.

[7] J. Braun, A. Kerber, M. Meringer, and C. Rücker, "Similarity of molecular descriptors: the equivalence of Zagreb indices and walk counts," MATCH. Communications in Mathematical and in Computer Chemistry, vol. 54, no. 1, pp. 163-176, 2005.

[8] K. C. Das and I. Gutman, "Some properties of the second Zagreb index," MATCH Communications in Mathematical and in Computer Chemistry, vol. 52, pp. 103-112, 2004.

[9] T. Došlić, "On discriminativity of zagreb indices," Iranian Journal of Mathematical Chemistry, vol. 3, no. 1, pp. 25-34, 2012.

[10] M. Eliasi, A. Iranmanesh, and I. Gutman, "Multiplicative versions of first Zagreb index," MATCH Communications in Mathematical and in Computer Chemistry, vol. 68, no. 1, pp. 217-230, 2012.

[11] M. R. Farahani, "Some connectivity indices and zagreb index of polyhex nanotubes," Acta Chimica Slovenica, vol. 59, no. 4, pp. 779-783, 2012.

[12] M. R. Farahani, "Zagreb index, zagreb polynomial of circumcoronene series of benzenoid," Advances in Materials and Corrosion, vol. 2, no. 1, pp. 16-19, 2013.

[13] M. R. Farahani and M. P. Vlad, "Computing First and Second Zagreb index, First and Second Zagreb Polynomial of Capradesigned planar benzenoid series $\mathrm{Ca}_{n}\left(\mathrm{C}_{6}\right)$," Studia Universitatis Babes-Bolyai Chemia, vol. 58, no. 2, pp. 133-142, 2013.

[14] M. R. Farahani, "The first and second zagreb indices, first and second zagreb polynomials of $\mathrm{HAC}_{5} \mathrm{C}_{6} \mathrm{C}_{7}[\mathrm{p}, \mathrm{q}]$ and $\mathrm{HAC}_{5} \mathrm{C}_{7}[\mathrm{p}, \mathrm{q}]$ nanotubes," International Journal of Nanoscience and Nanotechnology, vol. 8, no. 3, pp. 175-180, 2012.

[15] M. R. Farahani, "Zagreb indices and Zagreb polynomials of pent-heptagon nanotube $\mathrm{VAC}_{5} \mathrm{C}_{7}(\mathrm{~S})$," Chemical Physics Research Journal, vol. 6, no. 1, pp. 35-40, 2013.

[16] M. R. Farahani, "The hyper-zagreb index of benzenoid series," Frontiers of Mathematics and Its Applications, vol. 2, no. 1, pp. $1-5,2015$.

[17] M. R. Farahani, "Computing the hyper-zagreb index of hexagonal nanotubes," Journal of Chemistry and Materials Research, vol. 2, no. 1, pp. 16-18, 2015.

[18] M. R. Farahani, "The hyper-zagreb index of TUSC4C8(S) nanotubes," International Journal of Engineering and Technology Research, vol. 3, no. 1, pp. 1-6, 2015.

[19] I. Gutman and K. C. Das, "The first Zagreb index 30 years after," MATCH. Communications in Mathematical and in Computer Chemistry, no. 50, pp. 83-92, 2004.

[20] D. Janežič, A. Miličević, S. Nikolić, N. Trinajstić, and D. Vukičević, "Zagreb indices: extension to weighted graphs representing molecules containing heteroatoms," Croatica Chemica Acta, vol. 80, no. 3-4, pp. 541-545, 2007.
[21] S. Nikolić, G. Kovačević, A. Miličević, and N. Trinajstić, "The Zagreb indices 30 years after," Croatica Chemica Acta, vol. 76, no. 2, pp. 113-124, 2003.

[22] D. Vukičević, S. Nikolić, and N. Trinajstić, "On the path-Zagreb matrix," Journal of Mathematical Chemistry, vol. 45, no. 2, pp. 538-543, 2009.

[23] D. Vukičević and N. Trinajstić, "On the discriminatory power of the Zagreb indices for molecular graphs," MATCH. Communications in Mathematical and in Computer Chemistry, vol. 53, no. 1, pp. 111-138, 2005.

[24] K. Xu and K. C. Das, "Trees, unicyclic, and bicyclic graphs extremal with respect to multiplicative sum Zagreb index," MATCH. Communications in Mathematical and in Computer Chemistry, vol. 68, no. 1, pp. 257-272, 2012.

[25] B. Zhou, "Zagreb indices," MATCH Communications in Mathematical and in Computer Chemistry, vol. 52, pp. 113-118, 2004.

[26] B. Zhou and I. Gutman, "Further properties of Zagreb indices," MATCH. Communications in Mathematical and in Computer Chemistry, vol. 54, no. 1, pp. 233-239, 2005.

[27] B. Zhou and I. Gutman, "Relations between Wiener, hyperWiener and Zagreb indices," Chemical Physics Letters, vol. 394, no. 1-3, pp. 93-95, 2004.

[28] B. Zhou and N. Trinajstić, "Some properties of the reformulated Zagreb indices," Journal of Mathematical Chemistry, vol. 48, no. 3, pp. 714-719, 2010.

[29] B. Zhou and D. A. Stevanović, "Note on Zagreb indices," MATCH Communications in Mathematical and in Computer Chemistry, vol. 56, pp. 571-578, 2006.

[30] B. Zhou, "Upper bounds for the zagreb indices and the spectral radius of series-parallel graphs," International Journal of Quantum Chemistry, vol. 107, no. 4, pp. 875-878, 2007.

[31] B. Zhou, "Remarks on Zagreb indices," MATCH. Communications in Mathematical and in Computer Chemistry, vol. 57, no. 3, pp. 591-596, 2007.

[32] M. Randić, "On characterization of molecular branching," Journal of the American Chemical Society, vol. 97, no. 23, pp. 6609-6615, 1975.

[33] B. Zhou and N. Trinajstić, "On a novel connectivity index," Journal of Mathematical Chemistry, vol. 46, no. 4, pp. 1252-1270, 2009.

[34] B. Zhou and N. Trinajstić, "On general sum-connectivity index," Journal of Mathematical Chemistry, vol. 47, no. 1, pp. 210-218, 2010.

[35] S. Fajtlowicz, "On conjectures of GRAFFITI II," Congressus Numerantium, vol. 60, pp. 187-197, 1987.

[36] O. Favaron, M. Maheo, and J. F. Sacle, "Some eigenvalue properties in graphs (conjectures of Graffiti-II)," Discrete Mathematics, vol. 111, no. 1-3, pp. 197-220, 1993.

[37] L. Zhong, "The harmonic index for graphs," Applied Mathematics Letters, vol. 25, no. 3, pp. 561-566, 2012.

[38] L. Zhong, "The harmonic index on unicyclic graphs," Ars Combinatoria, vol. 104, pp. 261-269, 2012.

[39] L. Zhong and K. Xu, "The harmonic index for bicyclic graphs," Utilitas Mathematica, vol. 90, pp. 23-32, 2013.

[40] M. A. Iranmanesh and M. Salehi, "On the harmonic index and harmonic polynomial of Caterpillars with diameter four," Iranian Journal of Mathematical Chemistry, vol. 5, no. 2, pp. 3543, 2014.

[41] H. Deng, S. Balachandran, S. K. Ayyaswamy, and Y. B. Venkatakrishnan, "On the harmonic index and the chromatic 
number of a graph," Discrete Applied Mathematics, vol. 161, no. 16-17, pp. 2740-2744, 2013.

[42] J. Li and W. C. Shiu, "The harmonic index of a graph," The Rocky Mountain Journal of Mathematics, vol. 44, no. 5, pp. 1607-1620, 2014.

[43] J.-B. Lv, J. Li, and W. C. Shiu, "The harmonic index of unicyclic graphs with given matching number," Kragujevac Journal of Mathematics, vol. 38, no. 1, pp. 173-183, 2014.

[44] R. Wu, Z. Tang, and H. Deng, "A lower bound for the harmonic index of a graph with minimum degree at least two," Filomat, vol. 27, no. 1, pp. 51-55, 2013.

[45] U. E. Wiersum and L. W. Jenneskens, Gas Phase Reactions in Organic Synthesis, Edited by Y. Valle, Gordon and Breach Science Publishers, Amsterdam, The Netherlands, 1997.

[46] M. R. Farahani, "Some connectivity indices of polycyclic aromatic hydrocarbons PAHs," Advances in Materials and Corrosion, vol. 1, pp. 65-69, 2013.

[47] M. R. Farahani, "Zagreb indices and zagreb polynomials of polycyclic aromatic hydrocarbons," Journal of Chemica Acta, vol. 2, pp. 70-72, 2013.

[48] M. R. Farahani and W. Gao, "On Multiple zagreb indices of polycyclic aromatic hydrocarbons PAHk," Journal of Chemical and Pharmaceutical Research, vol. 7, no. 10, pp. 535-539, 2015.

[49] W. Gao and M. R. Farahani, “The Theta polynomial $\Theta(G, x)$ and the Theta index $\Theta(G)$ of molecular graph Polycyclic Aromatic Hydrocarbons $\mathrm{PAH}_{k}$," Journal of Advances in Chemistry, vol. 12, no. 1, pp. 3934-3939, 2015.

[50] M. R. Farahani, W. Gao, and M. R. Rajesh Kanna, "On the omega polynomial of a family of hydrocarbon molecules 'polycyclic aromatic hydrocarbons $\mathrm{PAH}_{\mathrm{k}}$,' Asian Academic Research Journal of Multidisciplinary, vol. 2, no. 7, pp. 263-268, 2015.

[51] M. R. Farahani and M. R. Rajesh Kanna, "The Pi polynomial and the Pi Index of a family hydrocarbons molecules," Journal of Chemical and Pharmaceutical Research, vol. 7, no. 11, pp. 253257, 2015.

[52] M. R. Farahani, W. Gao, and M. R. Rajesh Kanna, "The edgeszeged index of the polycyclic aromatic hydrocarbons PAHk," Asian Academic Research Journal of Multidisciplinary, vol. 2, no. 7, pp. 136-142, 2015. 

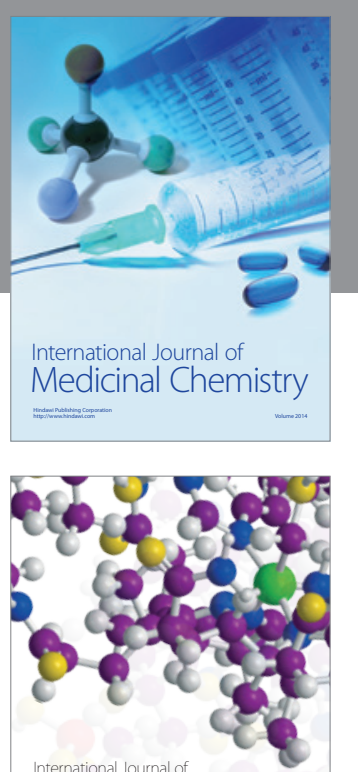

Carbohydrate Chemistry

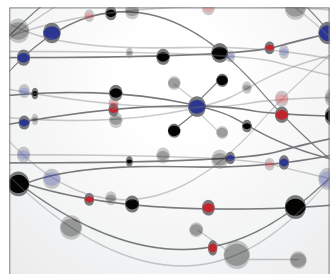

The Scientific World Journal
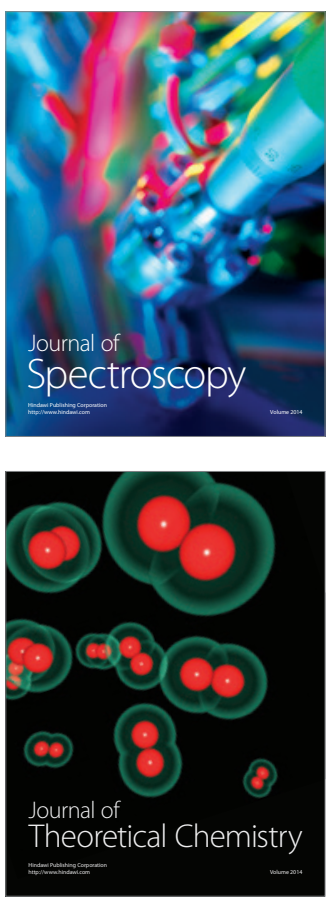
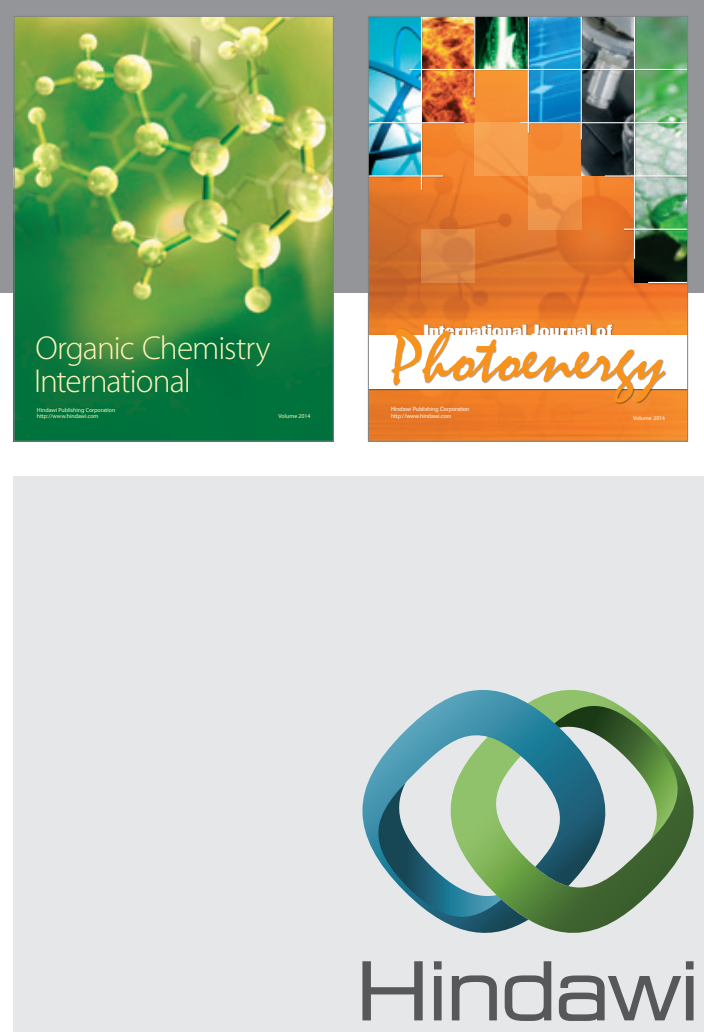

Submit your manuscripts at

http://www.hindawi.com

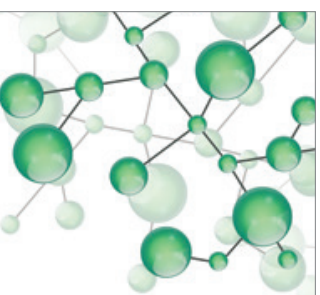

International Journal of

Inorganic Chemistry

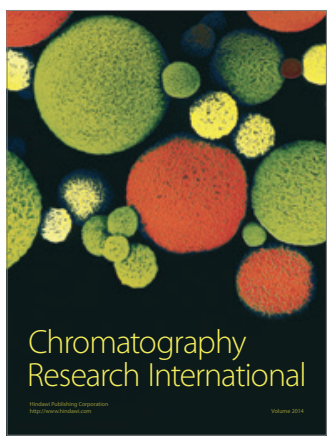

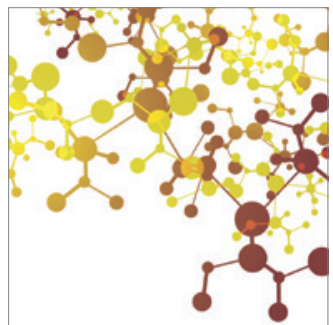

Applied Chemistry
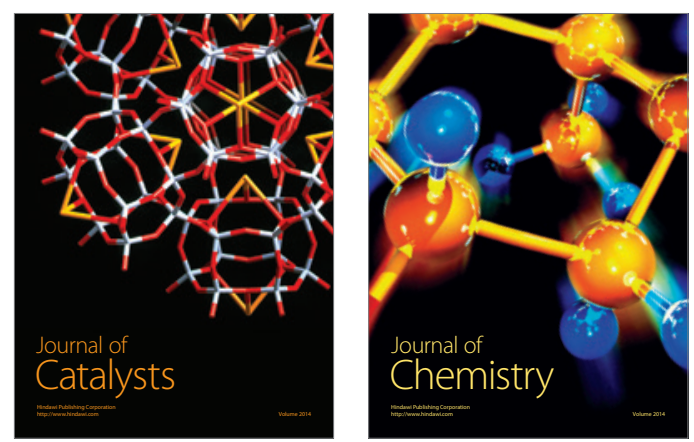
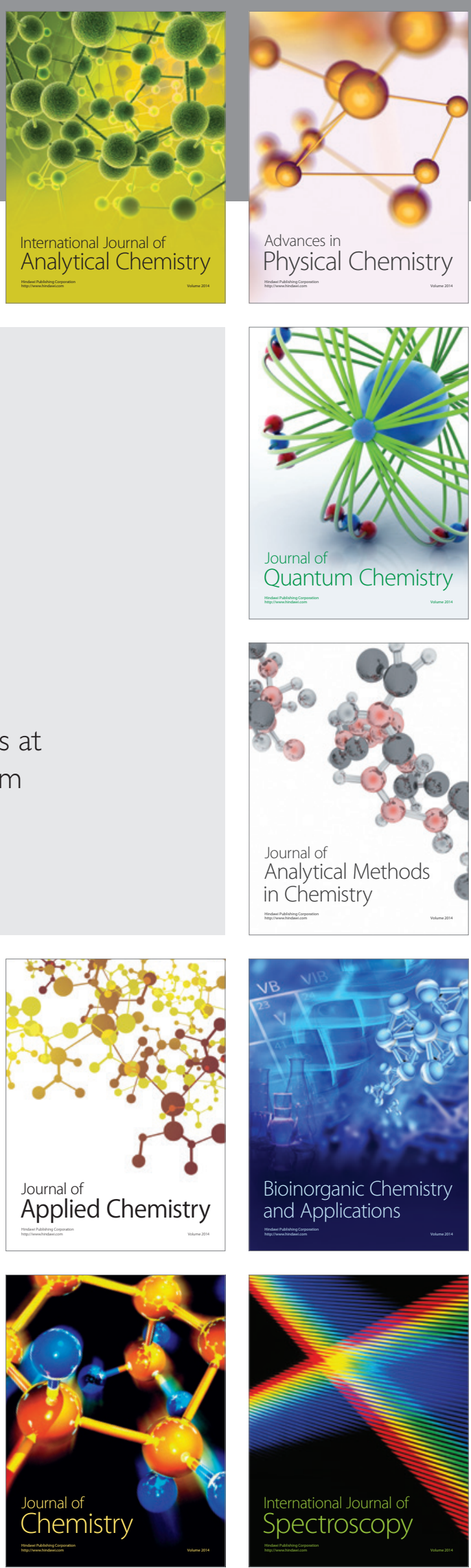